\title{
Analisis Survival dengan Pemodelan Regresi Cox Proportional Hazard Menggunakan Pendekatan Bayesian (Studi Kasus: Pasien Rawat Inap Penderita Demam Tifoid di RSUD Haji Makassar)
}

\author{
Adi Rahmat Faisal*, Muhammad Nadjib Bustan, \& Suwardi Annas \\ Program Studi Statistika, Fakultas Matematika dan Ilmu Pengetahuan Alam, Universitas Negeri Makassar, Indonesia
}

Keywords: Survival Analysis, Regression Cox Proportional Hazard, Thyfoid Fever.

\begin{abstract}
:
Analisis survival merupakan metode statistika yang digunakan untuk menganalisis data dimana peubah yang diperhatikan adalah waktu sampai terjadinya suatu event. Waktu dapat dinyatakan dalam tahun, bulan, minggu, atau hari dari awal mula dilakukan pengamatan pada seorang individu sampai suatu peristiwa terjadi pada individu. Salah satu tujuan analisis survival adalah untuk mengetahui hubungan antara waktu kejadian dan peubah bebas yang terukur pada saat dilakukan penelitian. Salah satu pendekatan metode regersi yang bisa digunakan adalah regresi Cox Proportional Hazard. Data yang digunakan dalam penelitian ini adalah data pasien penderita demam tifoid di RSUD Haji Makassar. Data demam tifoid memiliki karakteristik yang memungkinkan untuk dilakukan analisis dengan menggunakan regresi Cox Proportional Hazard. Adapun analisisnya menggunakan pendugaan parameter Bayesian, diperoleh faktor yang signifikan berpengaruh terhadap laju kesembuhan pasien adalah nyeri ulu hati. Nilai hazard ratio peubah nyeri ulu hati sebesar 0,63 . Nilai tersebut $<1$ sehingga dapat dikatakan bahwa pasien yang mengalami nyeri ulu hati memiliki laju kesembuhan 0,63 kali dibandingkan yang tidak mengalami nyeri ulu hati.
\end{abstract}

\section{Pendahuluan}

Analisis survival adalah salah satu metode statistika yang digunakan untuk menganalisis data dimana peubah yang diperhatikan adalah waktu sampai terjadinya suatu event. Waktu dapat dinyatakan dalam: bulan, minggu, atau hari dari awal mula dilakukan pengamatan pada seorang individu sampai suatu peristiwa terjadi pada individu tersebut (Kleinbaum \& Klein, 2005).

Tujuan analisis survival adalah untuk mengetahui hubungan antara waktu kejadian dengan peubah bebas yang terukur pada saat dilakukan penelitian. Selain itu, juga digunakan untuk melihat faktor-faktor yang secara signifikan berpengaruh pada suatu peristiwa atau kejadian.

Analisis survival umumnya menggunakan dua pendekatan, yaitu pendakatan parametrik dan nonparametrik. Analisis survival dengan pendekatan parametrik digunakan apabila data memenuhi distribusi tertentu, seperti Weibull, Eksponensial, Log Normal, maupun Gamma. Sedangkan analisis survival dengan pendekatan nonparametrik digunakan jika data tidak memenuhi salah satu distribusi. Model nonparametrik sering digunakan karena tidak melihat distribusi data dan juga aman ketika berada dalam keraguan untuk menentukan model parametriknya sehingga tidak

\footnotetext{
* Corresponding author.

E-mail address: adirahmatfaisal@gmail.com
} 
ada ketakutan tentang pemilihan model parametrik yang salah dan hasil pendugaannya hampir sama dengan hasil pendugaan model parametrik (Kleinbaum \& Klein, 2005).

Salah satu model statistika yang paling penting dalam penelitian medis adalah model Proportional Hazard. Model yang bersesuaian dengan penelitian ini adalah Cox Proportional Hazard. Model Cox Proportional Hazard juga tidak memerlukan fungsi baseline hazard yang terdapat pada model. Fungsi baseline hazard adalah fungsi hazard yang melibatkan waktu tapi tidak melibatkan kovariat.

Pendekatan yang digunakan dalam pendugaan parameternya adalah pendekatan Bayesian. Metode Bayesian lebih baik dalam menduga parameter dibandingkan pendekatan statistika klasik, Pendekatan Bayesian menggunakan prinsip distribusi probabilitas langsung pada parameternya (parameter dilakukan sebagai peubah). Hal ini memberikan kepercayaan yang lebih dibandingkan pendekatan statistika klasik pada umumnya. Pendekatan statistika klasik memandang parameter $\theta$ sebagai parameter bernilai tetap. Sedangkan pendekatan Bayesian memandang parameter $\theta$ sebagai peubah random yang mempunyai distribusi yang disebut distribusi prior. Dari distribusi prior selanjutnya dapat ditentukan distribusi posterior sehingga diperoleh estimator Bayesian yang merupakan mean atau modus dari distribusi posterior (Preatin, Yahya, \& Yos Rusdiansyah, 2007).

Penyelesaian masalah melalui pendekatan Bayesian mempunyai kelebihan dibandingkan dengan pendekatan klasik, karena pendekatan ini mengintegrasikan kondisi priornya ke dalam perhitungan selanjutnya (Niggli \& Musy, 2005). Keuntungan lain dari pendekatan Bayesian adalah inferensi dari parameter yang tidak diketahui langsung dari distribusi posterior nya dan mengakomodasi informasi-informasi sebelumnya dalam bentuk prior (Mengersen, 2009). Pendekatan Bayesian dilakukan dengan simulasi Markov Chain Monte Carlo (MCMC), karena dengan pendekatan ini kompleksitas dalam model lebih mudah diatasi. Hal ini dikarenakan pendekatan dengan Bayesian dapat dilakukan berdasarkan pada data yang ada, meskipun tidak ada asumsi distribusi pada data tersebut.

Pada penelitian ini data yang digunakan adalah data pasien rawat inap penderita demam tifoid di RSUD Haji Makassar tahun 2018, khusus daerah Provinsi Sulawesi Selatan, pada tahun 2013 tercatat jumlah penderita demam tifoid sebanyak 31.633 orang (Dinkes Sulsel, 2014). Penelitian sebelumnya yang dijadikan rujukan atau referensi berkaitan dengan demam tifoid maupun metode yang digunakan diantaranya, Rinni, Wuryandari, \& Rusgiyono (2014) yang berjudul pemodelan laju kesembuhan pasien rawat inap Typhus Abdominalis (demam tifoid) menggunakan model regresi kegagalan proporsional dari cox (Studi Kasus di RSUD Kota Semarang). Yusuf (2018) berjudul analisis survival lama waktu sembuh dengan perawatan standar pada pasien rawat inap penyakit tifus dengan menggunakan metode regresi Cox Proportional Hazard. (Studi Kasus: Di RS PKU Muhammadiyah Bantul Yogyakarta Tahun 20162017). Wijayanti, (2014) berjudul perbandingan analisis regresi cox dan analisis survival Bayesian pada ketahanan hidup pasien kanker serviks di RSUD Dr. Soetomo Surabaya. Sari, Wahyuningsih, \& Goejantoro (2013) berjudul Model Proportional Hazard Cox dengan Pendekatan Bayesian (Studi Kasus: Pasien Rawat Inap Demam Berdarah Dengue di Rumah Sakit Umum Daerah Abdul Wahab Sjahranie Samarinda). Berdasarkan latar belakang yang telah dipaparkan sebelumnya maka peneliti tertarik untuk melakukan penelitian yang berjudul "Analisis Survival dengan Pemodelan Regresi Cox Proportional Hazard Menggunakan Pendekatan Bayesian. (Studi Kasus: Pasien Rawat Inap Penderita Demam Tifoid di RSUD Haji Makassar)".

\section{Tinjauan Pustaka}

\subsection{Analisis Survival}

Analisis survival adalah metode statistika yang digunakan untuk menganalisis data yang bertujuan untuk mengetahui hasil dari peubah yang mempengaruhi suatu awal kejadian sampai akhir kejadian, misalnya waktu yang dicatat dalam hari, minggu, bulan dan tahun. Untuk kejadian awal misalkan pasien terjangkit penyakit dan untuk kejadian akhir misalkan kematian pasien dan kesembuhan pasien (Kleinbaum \& Klein, 2005). 
Menurut Jakperik \& Ozoje (2012) dalam analisis survival, ada istilah failure (meskipun peristiwa sebenarnya mungkin saja sukses) yaitu suatu kejadian dimana tercatatnya kejadian yang diinginkan. Dalam menentukan waktu survival, ada tiga faktor yang dibutuhkan:

a. Waktu awal pencatatan (star point) adalah waktu awal dimana dilakukannya pencatatan untuk menganalisis suatu kejadian.

b. Waktu akhir pencatatan (end point) adalah waktu pencatatan berakhir. Waktu ini berguna untuk mengetahui status tersensor atau tidak tersensor seseorang pasien untuk bisa melakukan analisis.

c. Skala pengukuran sebagai batas dari waktu kejadian dari awal sampai akhir kejadian. Skala diukur dalam hari, minggu atau tahun.

Beberapa tujuan analisis survival adalah sebagai berikut:

a. Mengestimasi dan menginterpretasikan fungsi survival dan fungsi hazard dari data survival

b. Membandingkan fungsi survival dan fungsi hazard.

c. Mengetahui pengaruh dari variabel independent terhadap waktu survival.

Jika akhir pencatatan dalam penelitian adalah kematian seorang pasien, maka hasil data tersebut dikatakan sebagai waktu survival. Namun kejadian tidak selalu berujung kematian, biasa juga mengenai sembuhnya pasien dari penyakit, berkurangnya gejala penyakit, atau kambuhnya pasien dari gejala tertentu. Menurut Kleinbaum dan Klein (2005), dalam analisis survival terdapat empat jenis penyensoran, yaitu:

1. Sensor kanan

2. Sensor kiri

3. Sensor selang

\subsection{Fungsi Survival dan Fungsi Hazard}

Fungsi Survival $S(t)$ didefinisikan sebagai probabilitas suatu objek bertahan setelah waktu ke- $t$. persamaan dapat dituliskan sebagai berikut:

$$
\begin{aligned}
S(t) & =P(T \geq t) \\
& =\int_{t}^{\infty} f(t) d t
\end{aligned}
$$

Definisi fungsi distribusi kumulatif dari T, fungsi survival dapat dinyatakan sebagai berikut:

$$
\begin{aligned}
S(t) & =P(T \geq t) \\
& =1-P(T \leq t) \\
& =1-F(t) \\
F(t) & =1-S(t) \\
& \frac{d(F(t))}{d t}=\frac{d(1-S(t))}{d t} \\
& f(t)=-\frac{d(S(t))}{d t}=-S^{\prime}(t)
\end{aligned}
$$

Probabilitas suatu individu mati dalam interval waktu dari $t$ sampai $t+\Delta \mathrm{t}$, jika diketahui individu tersebut masih dapat bertahan hidup sampai dengan waktu $t$ dinyatakan sebagai fungsi hazard. Secara matematis, fungsi hazard dinyatakan sebagai berikut:

$h(t)=\lim _{\Delta t \rightarrow 0} \frac{P(t \leq T<t+\Delta t \mid T \geq t)}{\Delta t}$

Misalkan $f(t)$ adalah fungsi densitas probabilitas pada waktu $t$, maka diperoleh:

$$
h(t)=\lim _{\Delta t \rightarrow 0} \frac{P(t \leq T<t+\Delta t \mid T \geq t)}{\Delta t}
$$




$$
\begin{aligned}
& =\lim _{\Delta t \rightarrow 0}\left[\frac{P[(t \leq T<(t+\Delta t)) \cap(T \geq t)]}{P(T \geq t) \Delta t}\right] \\
& =\lim _{\Delta t \rightarrow 0}\left[\frac{P(t \leq T<t+\Delta t)}{P(T \geq t) \Delta t}\right] \\
& =\lim _{\Delta t \rightarrow 0}\left[\frac{1}{\Delta t} \frac{P(T<t+\Delta t)-P(T \leq t)}{P(T \geq t)}\right] \\
& =\lim _{\Delta t \rightarrow 0}\left[\frac{1}{\Delta t} \frac{F(t+\Delta t)-F(t)}{1-F(t)}\right] \\
& =\frac{1}{S(t)} \lim _{\Delta t \rightarrow 0} \frac{F(t+\Delta t)-F(t)}{\Delta t} \\
& =\frac{F^{\prime}(t)}{S(t)} \\
& =\frac{f(t)}{S(t)}
\end{aligned}
$$

\subsection{Asumsi Proportional Hazard}

Asumsi Proportional Hazard dikatakan terpenuhi adalah apabila sebuah garis pada kurva survival (antar kelompok) tidak saling berpotongan. Asumsi Proportional Hazard sangat penting dalam analisis survival. Analisis survival yang memenuhi asumsi Proprotional Hazard akan dianalisis dengan analisis time independen, sementara survival yang tidak memenuhi asumsi Proportional Hazard akan dianalisis dengan analisis full model atau analisis reduced model. Salah satu pendekatan yang sering digunakan dalam mengecek asumsi Proprotional Hazard adalah pendekatan grafik. Pendekatan grafik merupakan metode yang digunakan dalam mengecek asumsi Proportional Hazard dengan melihat garis survival pada kurva Kapplan - Meier. Asumsi terpenuhi apabila garis survival tidak saling berpotongan (Kleinbaum \& Klein, 2005).

Menurut Dahlan (1994), proses pengecekan asumsi proportional hazard, dapat dilakukan dengan tiga jenis cara, yaitu sebagai berikut:

a. Garis survival pada kurva Kapplan - Meier tidak saling berpotongan

b. Garis survival pada ln-ln survival tidak saling berpotongan

c. Uji global test atau Goodness of Fit (GOF)

Dari ketiga jenis pengecekan asumsi Proportional Hazard, pada penelitian ini menggunakan pengecekan asumsi dengan uji global test. Jika asumsi telah terpenuhi, maka model Cox Proportional Hazard dapat dibentuk. Salah satu tujuan model Cox Proportional Hazard adalah untuk memodelkan hubungan antara waktu survival dengan peubahpeubah yang diduga mempengaruhi waktu survival.

Pengecekan asumsi Proportional Hazard pada data dilakukan sebagai berikut:

Hipotesis dari uji global test:

$\mathrm{H}_{0}$ : Data memenuhi asumsi Proportional Hazard

$\mathrm{H}_{1}$ : Data tidak memenuhi asumsi Proportional Hazard

Signifikansi $\alpha$ : 0,05

Penolakan $\mathrm{H}_{0}$ jika p-value $<\alpha$ artinya data memenuhi asumsi Proportional Hazard.

\subsection{Model Regresi Cox Proportional Hazard}

Pada analisis survival terdapat dua model, yaitu parametrik dan nonparametrik. Model parametrik antara lain model Weibull yang berdistribusi Weibull dan model exponensial yang berdistibusi eksponensial. Model regresi Cox Proportional Hazard merupakan model nonparametrik karena model Cox Proprotional Hazard tidak memerlukan informasi tentang distribusi yang mendasari waktu survival dan parameter regresi dapat di estimasi dari model (Lee \& Wang, 2003). Model Cox Proportional Hazard adalah model nonparametrik yang digunakan dalam analisis survival. 
Model Cox Proportional Hazard memiliki kelebihan karena tidak memiliki asumsi terkait dengan sifat dan bentuk seperti pada asumsi regresi lain yang peubah bebasnya harus mengikuti distribusi tertentu (Septi \& Purhadi, 2016).

Menurut Kleinbaum \& Klein, 2005 Model Cox Proportional Hazard dapat dituliskan sebagai berikut:

Dimana:

$$
h_{i}(t)=h_{0}(t) \exp \left(\beta_{1} x_{1}+\beta_{2} x_{2}+\ldots+\beta_{p} x_{p}\right)=h_{0}(t) e^{\Sigma_{j=1}^{p} \beta_{j} x_{j}}
$$

$$
\begin{array}{ll}
h_{i}(t) & =\text { fungsi kegagalan individu ke }-i \\
h_{0}(t) & =\text { fungsi kegagalan dasar }(\text { fungsi Hazard }) \\
x_{j} & =\text { nilai peubah ke }-j, \text { dengan } j=1,2, \ldots, \mathrm{p} \\
\beta_{j} & =\text { Koefisien regresi ke }-j, \text { dengan } j=1,2, \ldots, \mathrm{p}
\end{array}
$$

\subsection{Pendekatan Bayesian}

Penaksiran parameter secara umum terdiri dari dua, yaitu dengan menggunakan pendekatan statistika klasik dan pendekatan statistika Bayesian. Statistika klasik sepenuhnya menggunakan proses inferensi pada data sampel yang diambil dari populasi. Sedangkatan pendekatan statistika Bayesian selain menggunakan data sampel dari populasi, juga melihat distribusi awal yang disebut distribusi prior. Keuntungan menggunakan metode Bayesian dibandingkan pendekatan statitika klasik terdapat pada informasi kondisi prior dalam proses pengolahan atau inferensia data. Pendekatan Bayesian menggunakan prinsip distribusi probabilitas langsung pada parameternya (parameter diberlakukan sebagai peubah), hal ini memberikan kepercayaan yang lebih di banding secara statistika klasik pada umumnya. Teori Bayesian merupakan alat bantu estimasi model yang dapat digunakan untuk menyelesaikan berbagai persoalan untuk berbagai situasi. Statistika Bayesian merupakan cara yang sederhana untuk mempelajari parameter yang bermasalah dalam model. Teori Bayesian memberikan cara untuk mendapatkan distribusi prediksi untuk masa mendatang. Hal ini tidak selalu mudah dikerjakan dengan cara statistika klasik pada umumnya. (Preatin et al., 2007).

\subsection{Hazard ratio}

Hazard ratio terbagi atas dua, sebagai berikut:

a. Hazard Ratio data kontinu

Hazard ratio untuk data kontinu adalah sebagai berikut:

$$
\widehat{H R}(c)=e^{c \beta}
$$

Interpretasi dari nilai estimator HR pada persamaan adalah resiko lebih lambat meninggal peubah akan bertambah sebesar untuk setiap pertambahan unit peubah.

b. Hazard ratio data kategori.

Hazard ratio untuk data kategori adalah sebagai berikut:

$$
\widehat{H R}=\frac{h(t \mid x=1)}{h(t \mid x=0)}=\frac{h(t) e^{\widehat{\beta}}}{h(t)}=e^{\widehat{\beta}}
$$

Ukuran yang digunakan untuk mengetahui resiko lebih lambat meninggal dapat diketahui dengan nilai hazard ratio. Hazard ratio merupakan perbandingan antara individu dengan kondisi peubah bebas x pada kategori sukses dengan kategori gagal. Hubungan antara peubah $\mathrm{x}$ dan dinyatakan dengan $\mathrm{h}(\mathrm{t} \mid \mathrm{x})$. Maka hazard ratio untuk individu dengan $\mathrm{x}=1$ dibandingkan $\mathrm{x}=0$ (Kleinbaum \& Klein, 2005). 


\section{Metode Penelitian}

\subsection{Sumber Data}

Data yang digunakan dalam penelitian ini adalah data sekunder. Data diperoleh dari rekam medis pasien demam tifoid RSUD Haji Makassar Tahun 2018.

\subsection{Definisi Operasional Peubah}

\begin{tabular}{|c|c|c|c|}
\hline Peubah & Nama Peubah & Jenis & Deskriptif \\
\hline $\mathrm{Y}$ & Waktu survival $(t)$ & Kontinu & $\begin{array}{l}\text { Waktu selama pasien demam tifoid menjalani rawat Inap di } \\
\text { Rumah Sakit (hari). }\end{array}$ \\
\hline S & Status & Kategori & $\begin{array}{l}\mathrm{s}=0 \text {, Jika pasien pulang paksa, atau pindah pengobatan, } \\
\text { meninggal selama periode penelitian } \\
\mathrm{s}=1 \text {, Jika pasien sembuh }\end{array}$ \\
\hline $\mathrm{X}_{1}$ & Usia & Kontinu & - \\
\hline $\mathrm{X}_{2}$ & Jenis Kelamin & Kategori & $\begin{array}{l}0=\text { Laki-laki } \\
1=\text { Perempuan }\end{array}$ \\
\hline $\mathrm{X}_{3}$ & Diare & Kategori & $\begin{array}{l}0=\text { Tidak mengalami diare } \\
1=\text { Mengalami diare }\end{array}$ \\
\hline $\mathrm{X}_{4}$ & Lidah Kotor & Kategori & $\begin{array}{l}0=\text { Tidak mengalami lidah kotor } \\
1=\text { Mengalami lidah kotor }\end{array}$ \\
\hline $\mathrm{X}_{5}$ & Nyeri Ulu Hati & Kategori & $\begin{array}{l}0=\text { Tidak mengalami nyeri ulu hati } \\
1=\text { Mengalami nyeri ulu hati }\end{array}$ \\
\hline $\mathrm{X}_{6}$ & Muntah & Kategori & $\begin{array}{l}0=\text { Tidak mengalami muntah } \\
1=\text { Mengalami muntah }\end{array}$ \\
\hline
\end{tabular}

\subsection{Teknik Analisis}

Dalam penelitian ini, teknik analisis data terdiri dari:

1. Eksplorasi Data.

Pada persiapan data, awalnya peneliti telah menemukan waktu survival $t$ yaitu:

a. Time origin or starting point (titik awal). Titik awal pada penelitian ini adalah waktu masuk pasien rawat inap demam tifoid di rumah sakit.

b. Ending event of Interest (kejadian akhir). Titik akhir yang dimaksud pada penelitian adalah tanggal dimana pasien rawat inap demam tifoid yang dinyatakan keluar dari rumah sakit dalam keadaan sembuh.

c. Measurement scale for the passage of time (skala ukuran untuk berlalunya waktu). Dalam penelitian ini skala yang digunakan adalah lama pasien demam tifoid yang rawat inap di rumah sakit dalam satuan hari.

2. Analisis deskriptif terhadap peubah bebas serta peubah terikat.

3. Uji distribusi waktu survival menggunakan uji Anderson Darling

4. Pengujian Asumsi Proportional Hazard dengan uji global test.

5. Pemodelan Regresi Cox Proportional Hazard

Pada pemodelan regresi Cox Proportional Hazard menggunakan metode Bayesian Markov Chain Monte Carlo dengan pembangkit peubah Gibbs Sampling.

6. Interpretasi Hasil

Interpretasi hasil menjelaskan hasil dari kesignifikanan peubah bebas yang terkait dalam model yang cocok.

7. Kesimpulan

Menyimpulkan hasil secara keseluruhan analisis data yang telah diolah. Pada tahap ini dapat ditarik kesimpulan, peubah bebas apa yang paling berpengaruh pada peubah terikat. 


\section{Hasil dan Pembahasan}

\subsection{Deskripsi Data Penelitian}

Penelitian dengan analisis survival ini melibatkan 90 sampel pasien rawat inap penderita demam tifoid di RSUD Haji Makassar pada tahun 2018, dimana pasien rata-rata mendapatkan perawatan selama hampir 5 hari, rata-rata usia pasien demam tifoid adalah 28 tahun dengan usia tertinggi 73 tahun dan usia terendah 2 tahun. Kemudian selama periode januari sampai desember 2018, pasien penderita demam tifoid di RSUD Haji Makassar lebih banyak yang berjenis kelamin perempuan. Untuk gejala diare hanya dialami sebagian kecil pasien demam tifoid, begitu juga dengan gejala lidah kotor yang tidak dialami sebagian besar pasien demam tifoid. Pasien yang mengalami nyeri ulu hati lebih banyak dibandingkan yang tidak mengalami, serta gejala muntah yang lebih banyak dialami pasien.

\subsection{Pengujian Distribusi Waktu Survival}

Tabel 1 Hasil Pengujian pada Data Waktu Survival

\begin{tabular}{clccc}
\hline No & \multicolumn{1}{c}{ Jenis Distribusi } & Anderson Darling Hitung & Anderson Darling Tabel & Hasil \\
\hline 1 & Weibull & 3,98 & 0,75 & Tolak $\mathrm{H}_{0}$ \\
2 & Gamma & 3,22 & 0,75 & Tolak $\mathrm{H}_{0}$ \\
3 & LogNormal & 3,29 & 0,75 & Tolak $\mathrm{H}_{0}$ \\
4 & Eksponensial & 24,74 & 1,3 & ${\text { Tolak } \mathrm{H}_{0}}$ \\
\hline
\end{tabular}

Dari tabel 1 dapat dilihat bahwa nilai setiap Anderson Darling hitung lebih besar dari nilai Anderson Darling tabel, sehingga waktu survival $(t)$ tidak ada yang memenuhi distribusi tertentu. Sehingga dapat disimpulkan bahwa data waktu survival tdak memiliki distribusi.

\subsection{Pengujian Asumsi Proportional Hazard}

Tabel 2 Pengujian Asumsi Proportional Hazard

\begin{tabular}{lccc}
\hline \multicolumn{1}{c}{ Peubah } & Korelasi & $P$ - Value & Keterangan \\
\hline Usia $\left(\mathrm{X}_{1}\right)$ & 0,18 & 0,07 & Gagal Tolak $\mathrm{H}_{0}$ \\
Jenis Kelamin $\left(\mathrm{X}_{2}\right)$ & 0,10 & 0,29 & Gagal tolak $\mathrm{H}_{0}$ \\
Lidah Kotor $\left(\mathrm{X}_{3}\right)$ & 0,00 & 0,97 & Gagal tolak $\mathrm{H}_{0}$ \\
Diare $\left(\mathrm{X}_{4}\right)$ & $-0,02$ & 0,76 & Gagal tolak $\mathrm{H}_{0}$ \\
Nyeri Ulu Hati $\left(\mathrm{X}_{5}\right)$ & 0,04 & 0,67 & Gagal tolak $\mathrm{H}_{0}$ \\
Muntah $\left(\mathrm{X}_{6}\right)$ & 0,07 & 0,49 & Gagal tolak $\mathrm{H}_{0}$ \\
\hline
\end{tabular}

Berdasarkan tabel 2 menunjukkan bahwa hasil dari uji Global Test untuk setiap peubah, masing-masing peubah memikili nilai P-Value > 0,05, maka dapat disimpulkan bahwa gagal tolak $\mathrm{H}_{0}$ yang berarti tidak cukup bukti untuk membuktikan bahwa data tersebut tidak memenuhi asumsi Proportional Hazard.

\subsection{Pendugaan Parameter dengan Pendekatan Bayesian}

Tabel 3 Estimasi Parameter menggunakan Pendekatan Bayesian.

\begin{tabular}{lcccc}
\hline \multicolumn{1}{c}{ Peubah } & Rerata & Batas Bawah & Batas Atas & Keterangan \\
\hline Usia $\left(\mathrm{X}_{1}\right)$ & 0,00 & $-0,01$ & 0,02 & Tidak Signifikan \\
Jenis Kelamin $\left(\mathrm{X}_{2}\right)$ & $-0,38$ & $-0,91$ & 0,06 & Tidak Signifikan \\
\hline
\end{tabular}




\begin{tabular}{lcccl}
\hline \multicolumn{1}{c}{ Peubah } & Rerata & Batas Bawah & Batas Atas & \multicolumn{1}{c}{ Keterangan } \\
\hline Lidah Kotor $\left(\mathrm{X}_{3}\right)$ & $-0,16$ & $-0,60$ & 0,29 & Tidak Signifikan \\
Diare $\left(\mathrm{X}_{4}\right)$ & $-0,28$ & $-0,76$ & 0,13 & Tidak Signifikan \\
Nyeri Ulu Hati $\left(\mathrm{X}_{5}\right)$ & 0,45 & 0,04 & 0,76 & Signifikan \\
Muntah $\left(\mathrm{X}_{6}\right)$ & 0,31 & $-0,02$ & 0,93 & Tidak Signifikan \\
\hline
\end{tabular}

Berdasarkan Tabel 3 diperoleh hasil pendugaan parameter model cox proportional hazard dengan menggunakan pendekatan Bayesian, berdasarkan nilai batas atas dan batas bawahnya menunjukkan bahwa ada satu peubah yang berpengaruh signifikan dan enam lainnya tidak berpengaruh signifikan. Peubah yang berpengaruh signifikan yaitu peubah nyeri ulu hati $\left(\mathrm{X}_{5}\right)$, sedangkan peubah-peubah yang tidak berpengaruh signifikan yaitu usia $\left(\mathrm{X}_{1}\right)$, jenis kelamin $\left(\mathrm{X}_{2}\right)$, lidah kotor $\left(\mathrm{X}_{3}\right)$, diare $\left(\mathrm{X}_{4}\right)$, dan muntah $\left(\mathrm{X}_{6}\right)$. Sehingga diperoleh model regresi cox proportional hazard sebagai berikut:

$$
\mathrm{h}_{\mathrm{i}}(\mathrm{t})=\mathrm{h}_{0}(\mathrm{t}) \exp (0,45 \text { nyeri ulu hati) }
$$

\subsection{Hazard Ratio pada Penderita Demam Tifoid}

Tabel 4 Nilai Hazard Ratio untuk setiap peubah

\begin{tabular}{lcc}
\hline Peubah & $B$ & Hazard Ratio $\left(e^{-\widehat{\beta}}\right)$ \\
\hline Usia $\left(\mathrm{X}_{1}\right)$ & 0,00 & 1,00 \\
Jenis Kelamin $\left(\mathrm{X}_{2}\right)$ & $-0,38$ & 1,46 \\
Lidah Kotor $\left(\mathrm{X}_{3}\right)$ & $-0,16$ & 1,17 \\
Diare $\left(\mathrm{X}_{4}\right)$ & $-0,28$ & 1,32 \\
Nyeri Ulu Hati $\left(\mathrm{X}_{5}\right)$ & 0,45 & 0,63 \\
Muntah $\left(\mathrm{X}_{6}\right)$ & 0,31 & 0,73 \\
\hline
\end{tabular}

Berdasarkan tabel 4 dapat dilakukan interpretasikan terahadap peubah yang signifikan. Nilai hazard ratio dari peubah Nyeri Ulu Hati (X5) sebesar 0,63. Nilai tersebut kurang dari satu, sehingga dapat dikatakan bahwa pasien yang mengalami nyeri ulu hati memiliki laju kesembuhan 0,63 kali dibandingkan pasien yang tidak mengalami nyeri ulu hati.

\section{Kesimpulan}

Berdasarkan hasil penelitian dan pembahasan terkait dengan pemodelan regresi Cox Proportional Hazard pada kasus demam tifoid, dapat disimpulkan bahwa:

1. Pemodelan regresi Cox Proportional Hazard pada data pasien rawat inap penderita demam tifoid di RSUD Haji Makassar tahun 2018 sebagai berikut:

$$
h_{i}(t)=h_{0}(t) \exp (0.41 \text { nyeri ulu hati). }
$$

2. Faktor-faktor yang signifikan mempengaruhi laju kesembuhan pasien penderita demam tifoid adalah nyeri ulu hati. Dimana laju kesembuhan pasien penderita demam tifoid yang mengalami nyeri ulu hati sebesar 0,63 . Nilai tersebut $<1$ yang berarti bahwa penderita demam tifoid yang mengalami nyeri ulu hati memiliki laju kesembuhan 0,63 kali dibandingkan pasien yang tidak mengalami nyeri ulu hati.

\section{References}

Dahlan, C. (1994). Survival Data In Medical Research. London: Chapman And Hall.

Dinkes Sulsel. (2014). Profil Kesehatan 2013. Makassar: Dinas Kesehatan Provinsi Sulawesi Selatan.

Jakperik, D., \& Ozoje, M. O. (2012). Survival Analysis of Avarage Recovery Time of Tuberculosis Patient in Northen Region, Ghana. International Jurnal of Current Research, 4(09), 123-125.

Kleinbaum, D. G., \& Klein, M. (2005). Survival Analysis A self-Learning Text (second). New York: Springer.

Lee, E. T., \& Wang, J. W. (2003). Statistical Methods for Survival Data Analysis (Third). Canada: John Wiley \& 
Sons, Inc.

Mengersen, K. (2009). "Modul 1 Bayesian Analysis", Short Course on Bayesian Modelling. Institut Tekniologi Sepuluh November, Surabaya.

Niggli, M., \& Musy, A. (2005). A Bayeisan Combination Method of Flood Models : Principles and Aplication Result. In Agricultural Water Management (Vol. 7).

Preatin, Yahya, K., \& Yos Rusdiansyah. (2007). Analsis Survival degan Pendekatan Bayesian untuk Memodelkan Ketahanan Program KB pada Individu Ibu di Indoensia Tahun 2007. 1-40.

Rinni, B. A., Wuryandari, T., \& Rusgiyono, A. (2014). Pemodelan Laju Kesembuhan Pasien Rawat Inap Typhus Abdominalis (Demam Tifoid) Menggunakan Model Regresi Kegagalan Proporsional dari Cox (Studi Kasus di RSUD Kota Semarang). Gaussian, 3(2011), 31-40.

Sari, N. W. W., Wahyuningsih, S., \& Goejantoro, R. (2013). Model Proportional Hazard Cox dengan Pendekatan Bayesian (Studi Kasus : Rawat Inap Demam Berdarah Dengue di Rumah Sakit Umum Daerah Abdul Wahab Sjahranie Samarinda). Eksponensial, 4, 9-16.

Septi, Y., \& Purhadi, A. M. (2016). Analisis Faktor yang Memengaruhi Laju Kesembuhan Pasien Tuberkulosis Paru di RSUD Dr. Seotomo Tahun 2015 Menggunakan Regresi Weibull dan Regresi Cox Proportional Hazard. Jurnal Sains Dan Seni ITS, 5(2), 450-455.

Wijayanti, R. (2014). Perbandingan Analisis Regresi Cox dan Analisis Survival Bayesian pada Ketahanan Hidup Pasien Kanker Serviks di RSUD DR. Seotomo Surabaya. Institut Teknologi Sepuluh November Surabaya.

Yusuf, M. K. (2018). Analisis Survival Lama Waktu Sembuh dengan Perawatan Standar Pada Pasien Rawat Inap Penyakit Tifus dengan Menggunakan Metode Regresi Cox Proportional Hazard (Studi Kasus: Di RS PKU MUhammdiyah Bantul Yogyakarta Tahun 2016-2017). Universitas Islam Indonesia. 